\title{
Emotional Creativity Across Adulthood: Age is Negatively Associated with Emotional Creativity
}

\author{
Radek Trnka1,2, Martin Kuška ${ }^{1,2}$, Inna Čábelková ${ }^{3}$ \\ 1 Science and Research Department, Prague College of Psychosocial Studies, Milanska 471, Prague 15, 10900 \\ Czech Republic \\ ${ }^{2}$ Olomouc University Social Health Institute (OUSHI), Palacky University Olomouc, Univerzitni 22, 771 11 Olomouc, \\ Czech Republic \\ ${ }^{3}$ Faculty of Humanities, Charles University, U Krize 8, 15800 Prague 5, Czech Republic
}

Previous research has shown that cognitive creativity decreases in older adulthood. However, the impact of age on emotional creativity remains unknown. The main aim of the present study was to explore how emotional creativity differs across adulthood. A total of 407 participants (251 women, 156 men) consisting of older, midlife and younger adults were administrated the Emotional Creativity Inventory $(\mathrm{ECl})$. A hierarchical multiple regression was used to determine whether emotional creativity differed with age. Age was negatively associated with the $\mathrm{ECl}$ total score and two components of the $\mathrm{ECl}$, emotional novelty and emotional preparedness. In contrast, emotional effectiveness/authenticity did not differ significantly across adulthood. The results indicate that the tendency to think about one's emotions and to evaluate them as novel and unique decreases with age, whereas the ability to respond effectively in situations requiring novel emotional responses remains relatively intact across adulthood.

Key words: emotional creativity, creative cognition, divergent thinking, aging, emotion regulation

\section{Introduction}

Emotional creativity (EC) is very important for healthy emotion regulation and thus also contributes to well-being (Morgan \& Scheibe, 2013; Schutte, Manes, \& Malouff, 2009), higher life satisfaction (Limonero, Tomas-Sabado, Fernandez-Castro, Gómez-Romero, \& ArdillaHerrero, 2012), better relationship satisfaction (Bloch, Haase, \& Levenson, 2014; Vater \& Schröder, 2015), effective coping with stress (Averill, 1999; Frolova \& Novoselova, 2015) and healthy aging (Hopp, Troy, \& Mauss, 2011). In contrast, ineffective emotional processing has been found to be linked with depression (Joormann \& Quinn, 2014), decreased job satisfaction (Blatný, Květon, Jelínek, Šolcová, Zábrodská, Mudrák, \& Machovcová, 2018) and a variety of psychiatric disorders, such as anxiety, post-traumatic stress disorder or obsessive-compulsive disorder (Banich, Mackiewicz, Depue, Whitmer, Miller, \& Heller, 2009).

The present study aims to explore the relationship between EC and age. The peak and decline model (Lindauer, 1998) suggests that creative cognitive abilities peak in early adulthood, and their decline starts when people are

Correspondence concerning this articlce should be addressed to Radek Trnka, Prague College of Psychosocial Studies (PVSPS), Milanska 471, Prague 15, 109 00, Czech Republic. E-mail: trnkar@volny.cz ORCID https://orcid.org/0000-0003-3731-468X

Received September 3, 2019 
in their 30 s or 40 s. However, very little is known about age-related changes in EC. EC is a pattern of cognitive abilities related to originality and appropriateness in emotional experience (Averill, 1999; Ivcevic, Brackett, \& Mayer, 2007). It involves one's ability to experience novel emotional experiences, think creatively about past emotional reactions and experiences or respond appropriately in situations requiring new or unusual emotional responses.

When comparing EC to standard definitions of creativity (Runco \& Jaeger, 2012), the first difference is that EC is related to the novelty of the subject's emotions, whereas the standard understanding of creativity is related to the novelty of the subject's ideas or products. However, regarding the basic principles, EC shares the criteria of originality as well as effectiveness with standard definitions of creativity. The criterion of originality in emotional experience is included directly in the basic definition of $E C$, because EC, like creativity, is suggested to benefit from flexible cognitive structures relating to the development of new ideas and products. EC has also been found to be related to the increased involvement of participants in creative leisure-time activities, e.g. creative writing, painting, composing music, dance improvisation, theatrical improvisation and do-it-yourself activities (Trnka, Zahradnik, \& Kuška, 2016).

Regarding the criterion of effectiveness, novel emotional reactions should also be effective and appropriate, because emotionally creative reactions should meet the demand of responding appropriately in interpersonal situations (Averill, 1999). Through this demand, EC also meets the criteria of practicality, relevance and adaptiveness to reality, which are closely related to standard definitions of creativity (Runco \& Jaeger, 2012). In contrast, it seems that cognitive abilities related to $E C$ do not necessarily require a problem-finding ability, because emotional processes are highly spontaneous and emergent in nature.

EC is related to both exploratory and generative cognitive processes (Finke, Ward, \& Smith, 1992). The experience of an unusual combination of discrete emotions, a variety of different emotions at the same time or responding to emotional situations in a unique manner requires cognitive flexibility in generative processes. This includes the generation of unique and unusual emotional experiences and reactions. In contrast, thinking about past emotional reactions and experiences requires processes such as memory retrieval, but also attribute finding and conceptual interpretation of past emotional events.

$E C$ is a complex phenomenon and links both cognitive and emotional processes. As mentioned above, there is a lack of evidence concerning age-related changes and EC (but see Trnka, Cabelkova, Kuška, \& Nikolai, 2019). To formulate working hypotheses for the present study, two fields of related research were stimulating: research on agerelated changes in the cognitive processing of emotions and research on age-related changes in creativity.

\section{Age-Related Changes in the Cognitive Pro- cessing of Emotions}

Research on age-related changes in the cognitive processing of emotions shows inconsistent results. One branch of this research has focused on age-related changes in emotional complexity, a construct that involves simultaneous experiencing of different emotions, fine-grained differentiating of one's emotions, distinguishing between one's own emotions and those of others, and expressing a varied and nuanced set of feelings (Grühn, Lumley, Diehl, \& Labouvie-Vief, 2013). Older adults showed less overall fluctuation in affect over time (Grühn et al., 2013) and less variability in negative affect over time (Carstensen, Pasupathi, Mayr, \& Nesselroade, 2000; Grühn et al., 2013), compared to younger adults. In contrast, Charles (2005) brought evidence about greater emotion heterogeneity in older age.

Hay and Diehl (2011) investigated age-related differences in two facets of emotional complexity: the co-occurrence of positive and negative affect and emotional differentiation 
(the ability to describe one's own emotions in a detailed fashion). Age was found to be negatively associated with emotional differentiation, as older adults showed lower emotional differentiation than younger adults. In contrast, the co-occurrence of positive and negative affect was not related to age.

Furthermore, Wurm (2011) brought empirical evidence supporting a hypothesis of the narrowing of affective space with increasing age. The narrowing of affective space refers to a reduction of the dimensionality of complex emotional situations and to a worsening of the ability to maintain complex representations with increasing age. The results of this study showed that participants of older age had less complex lexical representations than younger participants. These results indicate a kind of age-related worsening of lexical access to mental representations.

Research focused on exploration of the intensity of emotional experience has brought inconsistent results. On one hand, age has been found not to diminish the subjective intensity of both positive and negative affect in everyday life (Carstensen et al., 2000). On the other hand, older adults showed a more intense emotional experience when viewing acts of injustice compared to younger adults (Phillips, Henry, Hosie, \& Milne, 2008).

Interestingly, older adults showed improvements in the cognitive control of emotions, specifically in habitual use of problem-solving as an emotion-regulation strategy (Le Vigouroux, Pavani, Dauvier, Kop, \& Congard, 2017), in using positive reappraisal (Lohani \& Isaacowitz, 2014; Shiota \& Levenson, 2009), in habitual reappraisal use (John \& Gross, 2004; Le Vigouroux et al., 2017; Masumoto, Taishi, \& Shiozaki, 2016), in down-regulating feelings of disgust (Scheibe \& BlanchardFields, 2009) or in habitual suppression use (Brummer, Stopa, \& Bucks, 2014; Eldesouky \& English, 2018; Nolen-Hoeksema \& Aldao, 2011). These improvements are often ascribed to the benefits arising from the accumulation of experience with processing various emotions during the life course (Blanchard-Fields, 2007, 2009).

\section{Age-Related Changes in Creativity}

As mentioned above, EC is related to both generative and exploratory cognitive processes. Past research has revealed age-related decline in both generative and exploratory phases of the creative process (RoskosEwoldsen, Black, \& McCown, 2008). In contrast, linking EC with the construct of divergent thinking, otherwise frequently used as an indicator of creative potential, is not so easy.

Divergent thinking is generally defined as an open-ended mental process oriented toward finding new, appropriate and different solutions to a given problem (Guilford, 1967). This group of cognitive processes is activated during the handling of objects or during various creative performances. However, empirical studies seeking links between EC and divergent thinking have shown inconsistent results (Ivcevic, Brackett, \& Mayer, 2007; Martsksvishvili, Abuladze, Sordia, \& Neubauer, 2017; Zenasni \& Lubart, 2008). To explore possible conceptual similarities between EC and divergent thinking, a more detailed look at the structure of EC is needed.

EC consists of three different components: novelty, preparedness and effectiveness/authenticity (Averill, 1999). For example, emotional preparedness, including thinking about one's emotional reactions or seeking reasons for one's own feelings, cannot be expected to require the imagining of an alternative use for common objects, which is an important component of divergent thinking. Similarly, emotional novelty, denoting how a person perceives his or her emotions as being original, unique or uncommon, is much more linked to a selforiented processing of emotions than to cognitive processes that facilitate finding new solutions to a problem. The third component of $E C$, emotional effectiveness/authenticity, includes effective responding in situations requiring new or unusual emotional responses and the tendency to believe that emotions may help a person achieve his or her life goals This component could be considered to be interrelated with divergent thinking, in part be- 
cause appropriate responding in situations requiring novel emotional responses may also be expected to include the requirement of seeking novel experiential solutions to a given emotional situation.

For divergent thinking, a curvilinear age pattern with a peak before the age of 40 and a later decline with age have been found (Palmiero, 2015; Reese, Lee, Cohen, \& Puckett, 2001). However, some studies also did not find any age-related difference in divergent thinking (Palmiero, Di Giacomo, \& Passafiume, 2014; Roskos-Ewoldsen, Black, \& McCown, 2008) or found that the ability of older adults to think divergently is comparable to younger adults, but occurs at a slower rate (Foos \& Boone, 2008).

\section{The Present Study}

The main purpose of the present study was to explore EC in participants of different ages. Very little research has been conducted on the relationship between EC and age in recent times. Therefore, the insights from related research were used for the development of working hypotheses.

Emotional complexity shares some features with EC, for example, the simultaneous experience of different emotions or the expression of a varied set of feelings. Therefore, it may be used as a referential model when searching for a hypothetical age-related pattern. In emotional complexity, curvilinear age patterns with a peak in late middle adulthood and a decline in older age were found (Labouvie-Vief, Chiodo, Goguen, Diehl, \& Orwoll, 1995; Labouvie-Vief, Diehl, Jain, \& Zhang, 2007). Based on these findings, it can be hypothesized for the purposes of the present study:

Hypothesis 1. EC has a curvilinear age pattern with a peak in late middle adulthood and a decline in older age.

One of the three components of EC, emotional preparedness, is closely linked to thinking about one's emotional reactions and seeking reasons for one's own feelings. This construct seems to be related to emotional understanding, in other words, to how a person subjectively understands his/her own emo- tions. Subjective emotional understanding, similarly to emotional complexity, has been found to show curvilinear age patterns with a peak in late middle adulthood and a decline in older age (Labouvie-Vief, DeVoe, \& Bulka, 1989). Therefore, it can be hypothesized for the purpose of the present study:

Hypothesis 2. Emotional preparedness has a curvilinear age pattern with a peak in late middle adulthood and a decline in older age.

Furthermore, emotional novelty is linked with experiencing a great variety of emotions at the same time, experiencing uncommon combinations of emotions, undergoing unusual emotional reactions and responding to emotional situations in a unique manner (Averill, 1999). This construct shares some aspects with the person's overall variability in emotional experience and fluctuation in affect over time. In past research, older adults showed less overall fluctuation in affect over time (Grühn et al., 2013) and less variability in negative affect over time (Carstensen, Pasupathi, Mayr, \& Nesselroade, 2000; Grühn et al., 2013), in comparison to younger adults. Based on these findings, it can be hypothesized that:

Hypothesis 3. Age is negatively related to emotional novelty.

The third component of EC, emotional effectiveness/authenticity, includes effective responding in situations requiring new or unusual emotional responses and the tendency to believe that emotions may help a person achieve his or her life goals. This component can be considered to share some aspects with divergent thinking, in part because responding in situations requiring unusual emotional responses may also be expected to include the requirement of seeking novel experiential solutions to a given emotional situation. Divergent thinking showed a curvilinear age pattern with a peak before the age of 40 and a later decline with age (Palmiero, 2015; Reese, Lee, Cohen, \& Puckett, 2001). Therefore, it can be hypothesized that:

Hypothesis 4. Emotional effectiveness/authenticity has a curvilinear age pattern with a peak before the age of 40 and a decline in older age. 


\section{Methods}

\section{Participants}

A total of 407 participants (251 women, 156 men) participated in the present study. All were citizens of the Czech Republic. They ranged from 15 to 64 years of age $\left(M_{\text {age }}=39\right.$ years; $S D=16)$. The quota sampling method was used, thus assuring approximately equal proportions of genders and age groups. Given the fact that cognitive decline has been found to influence EC (Trnka et al., 2019) as well as emotional diversity in older adulthood (Ram, Gerstorf, Lindenberger, \& Smith, 2011), only adults younger than 65 were included in the present study to eliminate the bias that could occur due to different levels of cognitive decline in very old adults. Participants were asked about their current medication and chronic diseases by means of an anamnesis questionnaire during the contact phase. Those suffering from mental illnesses or psychiatric disorder that could potentially influence their emotionality (depression) were excluded from the sample. In addition, participants medicated by drugs that influence their emotionality (psychopharmaceutic drugs or antiepileptic drugs) were excluded from the sample.

The research design was approved by the institutional ethics committee. All participants provided signed informed consent with participation in the study. Signed parental informed consent was obtained in cases of participants younger than 18 years. Participants were assured about protecting the confidentiality of the research data.

\section{Measures}

At the beginning, each participant filled in the basic demographic characteristics. Afterwards, participants were administrated with a selfreport questionnaire measuring $\mathrm{EC}$.

EC was measured using the Emotional Creativity Inventory (ECI) (Averill, 1999), a self-report questionnaire. The $\mathrm{ECl}$ consists of 30 items rated on a 5-point scale, with anchors of
1 (strongly agree) and 5 (strongly disagree). The total score ranges from a low of 30 to a high of 150 . Two of the 30 items are reversely coded. The $\mathrm{ECl}$ has three subscales that reflect different facets of EC: Preparedness (items like "I think about and try to understand my emotional reactions"), Novelty (items like "My emotional reactions are different and unique") and Effectiveness/Authenticity (items like "I respond well in situations that call for new or unusual emotional responses" or "My outward emotional reactions accurately reflect my inner feelings"). The ECI is a widely accepted and used measure. The studies of Humphreys, Jiao, and Sadler (2008); Ivcevic, Brackett, and Mayer (2007); and Gutbezahl and Averill (1996) have provided evidence of the good construct and discriminant and incremental validity of the $\mathrm{ECl}$. Thus, the validity of this self-report questionnaire is considered acceptable for the purpose of the present study.

\section{Data Analysis}

To determine whether EC and its three components differed with age, a series of hierarchical multiple regression analyses that regressed emotional creativity and its component estimates onto age, controlling for differences in gender and education, was conducted. In order to estimate the effects of age after education and gender were entered, the first two steps of the hierarchical regression included gender and education (the first step, Formula 1) and gender, education and age (the second step, Formula 2). This enabled us to estimate the age contribution to variance explained in addition to that explained by gender and education. Then the possible U-shaped relationship of EC and its three components and age was tested by adding the squared term and moderating effects of demographic variables of education and gender by adding the interaction terms to the hierarchical regression framework (the third stage is depicted in Formula 3). Given that neither the age squared nor the interaction terms added significant explanatory power to the model and that the extended model showed significant multicollin- 
earity, the results of the third part of hierarchical regression are not reported here and only the results of the first two steps of hierarchical regression are presented.

$E C l_{\mathrm{i}}=b_{0}+b_{1}$ Gender $+b_{2} E d u+\xi$

$E C l_{\mathrm{i}}=b_{0}+b_{1}$ Gender $+b_{2} E d u+b_{3}$ Age $+\xi$

$E C l_{\mathrm{i}}=b_{0}+b_{1}$ Gender $+b_{2} E d u+b_{3} A g e+b_{4} A g e^{2}$ $+b_{5}$ AgeGender $+b_{6}$ AgeEdu $+\xi$

Where:

- $E C l$ denotes the $\mathrm{ECl}$ components Effectiveness/Authenticity $\left(\mathrm{ECl}_{\mathrm{ea}}\right)$, Preparedness $\left(\mathrm{ECl}_{\mathrm{p}}\right)$, Novelty $\left(\mathrm{ECI}_{\mathrm{n}}\right)$ and subsequently the Emotional Creativity Inventory in total $(\mathrm{ECl})$.

- Gender and Age stand for the gender and age of the participants

- Edu stands for education (primary, secondary, and higher). The variable was included as an ordinal variable as opposed to a series of dummy variables in order to maintain the character of ordinal data, though at the expense of possibly unequal differences between the categories (primary and secondary education, secondary and higher).
The $25^{\text {th }}$ version of the SPSS was employed to analyze the data. In order to increase the reliability of the results, a two-tailed $5 \%$ level of significance was chosen. Based on the central limit theorem, a normal distribution of the data was assumed.

\section{Results}

Our primary interest was to determine whether EC differed with age. To do so, the reliability of the questionnaire was estimated and Cronbach's alphas were computed for ECl and its three subscales: Novelty, Preparedness and Effectiveness/Authenticity. The Cronbach's alpha for $\mathrm{ECl}$ was .877 , and for the subscales of Novelty and Preparedness it was .821 and .801 , respectively, which represents very good consistency. The Cronbach's alpha for the Effectiveness/Authenticity subscale was .711, which represents good consistency (see Table 1).

The correlation and descriptive statistics for all continuous and categorical variables are listed in Table 1. Age proved to be significantly correlated with $\mathrm{ECl}$ and two of its components. The components of $\mathrm{ECl}$ itself were also sig-

Table 1 Descriptive statistics, reliability and correlations for all continuous variables

\begin{tabular}{|c|c|c|c|c|c|c|}
\hline & Age & $\mathrm{ECl}$ & $\mathrm{ECl}_{\mathrm{n}}$ & $\mathrm{ECl}_{\mathrm{p}}$ & $\mathrm{ECl}_{\mathrm{ea}}$ & Education \\
\hline $\mathrm{ECl}$ & $-.217^{\star \star \star *}$ & 1 & & & & \\
\hline $\mathrm{ECl}_{\mathrm{n}}$ & $-.238^{\star * *}$ & $.874^{* * *}$ & 1 & & & \\
\hline $\mathrm{ECl}_{\mathrm{p}}$ & $-.216^{\star * *}$ & $.796^{* * *}$ & $.537^{* * *}$ & 1 & & \\
\hline $\mathrm{ECl}_{\mathrm{ea}}$ & .024 & $.714^{* * *}$ & $.386^{\star * *}$ & $.476^{\star * *}$ & 1 & \\
\hline Education & $-.103^{*}$ & -.010 & -.044 & .061 & -.022 & 1 \\
\hline Mean & 39.46 & 97.01 & 41.83 & 25.39 & 29.74 & 2.50 \\
\hline Std. deviation & 15.53 & 16.39 & 9.29 & 5.45 & 5.51 & .55 \\
\hline Range & $14-64$ & $43-146$ & $18-70$ & $7-35$ & $13-45$ & $1-3$ \\
\hline$N$ & 407 & 398 & 403 & 406 & 401 & 407 \\
\hline $\begin{array}{l}\text { Cronbach's alpha } \\
\text { ( } N \text { of Items) }\end{array}$ & & $.877(30)$ & $.821(14)$ & $.801(7)$ & $.711(9)$ & \\
\hline
\end{tabular}


nificantly correlated. The relationship of ECI and components with the categorical variable (gender differences) is presented in Table 2. According to the $T$-test results presented in Table 2, women reported higher average emotional creativity scores in $\mathrm{ECl}$ and its components Preparedness and Effectiveness/Authenticity.

The standardized $\beta$ coefficient estimates, standard errors, $p$-values and Variance Inflation Factors (VIF) for the statistically significant steps of hierarchical regressions are listed in Tables 3, 4, 5, and 6. The plots of associations between $\mathrm{ECl}$ and its three components - Novelty $\left(\mathrm{ECl}_{\mathrm{n}}\right)$, Preparedness $\left(\mathrm{ECl}_{\mathrm{p}}\right)$ and Effective-
ness/Authenticity $\left(\mathrm{ECl}_{\mathrm{ea}}\right)$ - on the y-axes and Age of the respondents on the $x$-axes are presented in Figure 1. Tables 3-6 show that none of the VIF exceeds 5; thus, the multicollinearity was not high. The statistical significance of all four presented models was acceptable at $5 \%$ significance levels. The $\beta$ coefficients for age were negative and statistically significant in three out of four cases, showing that the $\mathrm{ECl}$ total score $(\beta=-0.219, p<.001)$ and its components Novelty $(\beta=-0.244, p<.001)$ and Preparedness $(\beta=-0.211, p<.001)$ were negatively associated with the age of the participants. In other words, the older the participants were, the lower EC and specifically lower emo-

Table 2 Gender differences in $E C l$ total score $(E C l)$, Novelty component $\left(E C I_{n}\right)$, Preparedness component $\left(E C l_{p}\right)$ and Effectiveness/Authenticity component $\left(E C l_{e a}\right)$

\begin{tabular}{lccccccc}
\hline & $\begin{array}{c}N \\
\text { women }\end{array}$ & $\begin{array}{c}N \\
\text { men }\end{array}$ & $\begin{array}{c}\text { Mean } \\
\text { women }\end{array}$ & $\begin{array}{c}\text { Mean } \\
\text { men }\end{array}$ & $\begin{array}{c}\text { Mean } \\
\text { Difference } \\
\text { (women-men) }\end{array}$ & $t$-value & $P$-value \\
\hline $\mathrm{ECl}$ & 243 & 155 & 98.69 & 94.37 & $4.32^{*}$ & 2.58 & .010 \\
$\mathrm{ECl}_{n}$ & 247 & 156 & 42.46 & 40.84 & 1.62 & 1.71 & .088 \\
$\mathrm{ECl}_{p}$ & 251 & 155 & 25.97 & 24.46 & $1.50^{* *}$ & 2.72 & .007 \\
$\mathrm{ECl}_{\text {ea }}$ & 245 & 156 & 30.25 & 28.94 & $1.31^{*}$ & 2.34 & .020 \\
\hline
\end{tabular}

Note. Levene's test of homogeneity of variances did not reject the null hypothesis of variance equality for all the variables. Statistical significance for mean differences: * $p<.05 ;{ }^{*} p<.01$; ${ }^{* * *} p<.001$ (2-tailed). The Ns vary across the subscales due to missing or unreadable responses in several cases.

Table 3 Association of ECl total score with age, controlling for gender and education

\begin{tabular}{lcccccc}
\hline Dependent variable & $\mathrm{ECl}$ & $\mathrm{Step} 1$ & \multicolumn{2}{c}{$\mathrm{ECl}$} & \multicolumn{2}{c}{ Step2 } \\
& $\beta$ & Sig. & $\mathrm{VIF}$ & $\beta$ & Sig. & VIF \\
\hline Gender & $-.129^{*}$ & .010 & 1.00 & $-.124^{*}$ & .011 & 1.00 \\
Education & -.013 & .800 & 1.00 & -.036 & .459 & 1.01 \\
Age & & & & $-.219^{* * *}$ & .000 & 1.01 \\
$R^{2}$ & .017 & & & .064 & & \\
$\Delta R^{2}$ & .017 & & & .047 & \\
$\Delta F$ & $3.354^{*}$ & .036 & & $19.858^{* * *}$ & .000 \\
$N$ & 397 & & & 397 & & \\
\hline
\end{tabular}

Note. Statistical significance: ${ }^{*} p<.05 ;{ }^{* *} p<.01 ;{ }^{* *} p<.001$ (2-tailed). Reference variables: women, higher education. The coefficients $\beta$ are standardized. We also tested the U-shaped model of the $\mathrm{ECl}$-age relationships. Age squared did not prove to be statistically significant in any of the regression, so we report the linear model only. 
tional novelty (the tendency to perceive their own emotions as being original, unique, uncommon and improbable), as well as lower emotional preparedness (the tendency to think about one's own emotional reactions and experiences), they reported. Thus, Hypothesis 3 , predicting a negative relationship of emotional novelty to age, was confirmed. However, the age patterns found for $\mathrm{ECI}$ total score and two components, Preparedness and Effectiveness/Authenticity, did not confirm the hypothesized curvilinear age pattern.

To test Hypotheses 1, 2, and 4, the possible U-shape relationships of EC with age by adding the quadratic term to the regression were specifically tested. However, the quadratic U-shape relationship was not statistically significant for $\mathrm{ECl}$ total score, nor for its three com-

Table 4 Association of the Novelty component of the $E C I\left(E C I_{n}\right)$ with age, controlling for gender and education

\begin{tabular}{|c|c|c|c|c|c|c|}
\hline Dependent variable & $\begin{array}{c}\mathrm{ECl}_{\mathrm{n}} \\
\beta\end{array}$ & $\begin{array}{l}\text { Step1 } \\
\text { Sig. }\end{array}$ & VIF & $\begin{array}{c}\mathrm{ECl}_{\mathrm{n}} \\
\beta\end{array}$ & $\begin{array}{c}\text { Step2 } \\
\text { Sig. }\end{array}$ & VIF \\
\hline Gender & -.086 & .086 & 1.00 & -.081 & .096 & 1.00 \\
\hline Education & -.045 & .369 & 1.00 & -.071 & .148 & 1.01 \\
\hline Age & & & & $-.244^{* * *}$ & .000 & 1.01 \\
\hline$R^{2}$ & .009 & & & .068 & & \\
\hline$\Delta R^{2}$ & .009 & & & .059 & & \\
\hline$\Delta F$ & 1.862 & .157 & & $25.112^{* * *}$ & .000 & \\
\hline$N$ & 402 & & & 402 & & \\
\hline
\end{tabular}

Note. Statistical significance: ${ }^{*} p<.05 ;{ }^{* *} p<.01 ;{ }^{* * *} p<.001$ (2-tailed). Reference variables: women, higher education. The coefficients $\beta$ are standardized. We also tested the U-shaped model of the ECl-age relationships. Age squared did not prove to be statistically significant in any of the regression, so we report the linear model only.

Table 5 Association of the Preparedness component of the $E C l\left(E C l_{p}\right)$ with age, controlling for gender and education

\begin{tabular}{lcccccc}
\hline Dependent variable & $\mathrm{ECl}_{\mathrm{p}}$ & $\mathrm{Step} 1$ & \multicolumn{2}{c}{$\mathrm{ECl}_{\mathrm{p}}$} & Step2 \\
& $\beta$ & $\mathrm{Sig}$. & $\mathrm{VIF}$ & $\beta$ & Sig. & VIF \\
\hline Gender & $-.133^{* *}$ & .007 & 1.00 & $-.132^{* *}$ & .007 & 1.00 \\
Education & .059 & .233 & 1.00 & .037 & .450 & 1.01 \\
Age & & & & $-.211^{* * *}$ & .000 & 1.01 \\
$R^{2}$ & .021 & & & .065 & & \\
$\Delta R^{2}$ & .021 & & & .044 & \\
$\Delta F$ & $4.425^{*}$ & .013 & & $18.897^{* \star *}$ & .000 \\
$N$ & 405 & & & 405 & & \\
\hline
\end{tabular}

Note. Statistical significance: ${ }^{*} p<.05 ;{ }^{* *} p<.01 ;{ }^{* * *} p<.001$ (2-tailed). Reference variables: women, higher education. The coefficients $\beta$ are standardized. We also tested the U-shaped model of the $\mathrm{ECl}$-age relationships. Age squared did not prove to be statistically significant in any of the regression, so we report the linear model only. 
Table 6 Association of the Effectiveness/Authenticity component of the $E C l(E C l$ ea) with age, controlling for gender and education

\begin{tabular}{|c|c|c|c|c|c|c|}
\hline \multirow[t]{2}{*}{ Dependent variable } & $\mathrm{ECl}_{\mathrm{ea}}$ & \multicolumn{2}{|l|}{ Step1 } & $\mathrm{ECl}_{\mathrm{ea}}$ & \multicolumn{2}{|l|}{ Step2 } \\
\hline & $\beta$ & Sig. & VIF & $\beta$ & Sig. & VIF \\
\hline Gender & $-.117^{*}$ & .020 & 1.00 & $-.116^{*}$ & .020 & 1.00 \\
\hline Education & -.024 & .630 & 1.00 & -.026 & .597 & 1.01 \\
\hline Age & & & & -.024 & .628 & 1.01 \\
\hline$R^{2}$ & .014 & & & .015 & & \\
\hline$\Delta R^{2}$ & .014 & & & .001 & & \\
\hline$\Delta F$ & 2.844 & .059 & & .235 & .628 & \\
\hline$N$ & 400 & & & 400 & & \\
\hline
\end{tabular}

Note. Statistical significance: ${ }^{*} p<.05 ;{ }^{* *} p<.01 ;{ }^{* * *} p<.001$ (2-tailed). Reference variables: women, higher education. The coefficients $\beta$ are standardized. We also tested the U-shaped model of the $\mathrm{ECl}$-age relationships. Age squared did not prove to be statistically significant in any of the regression, so we report the linear model only.

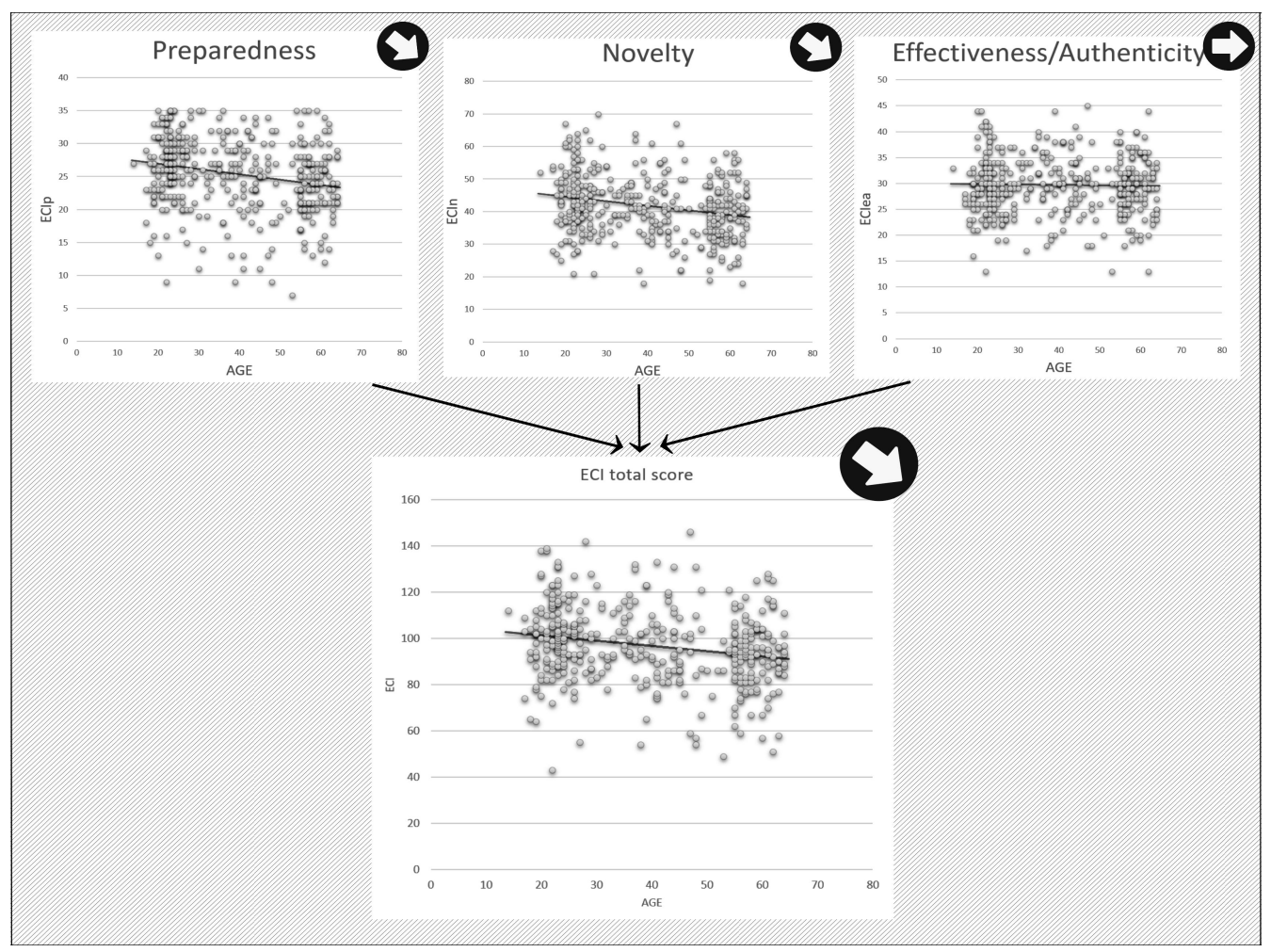

Figure 1 Plots of associations between $\mathrm{ECl}$ and its three components: Novelty, Preparedness and Effectiveness/Authenticity 
ponents, Novelty, Preparedness, and Effectiveness/Authenticity. Thus, Hypotheses 1, 2, and 4 were not confirmed, and neither EC nor any of its three components showed a curvilinear age pattern. Given that the U-shape was not statistically significant, and for the sake of conciseness of the paper, the results of U-shape relationships are not presented here.

Out of all the independent variables listed in Tables 3-6, age proved to explain the highest share of variability in the dependent variables. In the case of $\mathrm{ECl}$, age explained $4.7 \%$ of the variability, which is a statistically significant change from the $1.7 \%$ that was explained by gender and education altogether (Table 3). Similarly, in the case of Novelty, age was responsible for $5.9 \%$ of the variability, which is a significant shift from the $0.9 \%$ explained by education and gender only (Table 4). For Preparedness, age was responsible for $4.4 \%$ of the variability, which is a statistically significant increase from the $2.1 \%$ explained by gender and education only (Table 5 ). In the case of Effectiveness/Authenticity, age did not bring a statistically significant increase in $R^{2}$ and was not statistically related $\left(\Delta R^{2}=.001, \Delta F=.235\right.$, $p=.628$, Table 6).

Of the control variables, men proved to be less emotionally creative in $\mathrm{ECl}(\beta=-0.124$, $p=.011)$ and its Effectiveness/Authenticity $(\beta=$ $-0.116, p=.020)$ and Preparedness component $(\beta=-0.132, p=.007)$ than women. Education did not prove to be significantly related to EC.

\section{Discussion}

The results of the present study showed that age was negatively associated with the $\mathrm{ECl}$ total score and two components of $\mathrm{ECl}$, emotional novelty and emotional preparedness. Despite the present study not being a longitudinal one, the cross-sectional results indicate a linear decrease of EC with age, including a linear decrease of emotional novelty and emotional preparedness (Figure 1).

Interestingly, past cognitive developmental research has revealed curvilinear age patterns in emotional complexity, showing a clear peak in late middle adulthood and a decline in older age (Labouvie-Vief, Chiodo, Goguen, Diehl, \& Orwoll, 1995; Labouvie-Vief, Diehl, Jain, \& Zhang, 2007). Similarly, subjective emotional understanding also shows curvilinear age patterns, with a peak in late middle adulthood and a decline in older age (Labouvie-Vief, DeVoe, \& Bulka, 1989). In contrast to these findings, the results of the present study indicate a linear decrease of EC with age, despite the fact that a possible U-shaped relationship of EC with age was tested for (see the Results section). Contrasting the results of the present study with previous research indicates that EC shows a different, linear age pattern compared to the nonlinear age patterns found in emotional complexity and subjective emotional understanding.

The results of the present study showed that the older the participants were, the weaker was their tendency to evaluate their emotions as novel and unique. Furthermore, the results also indicated a linear decrease of emotional preparedness with age (Figure 1), which suggests a weakening of the tendency to think about one's emotional reactions and emotional experiences and to search for reasons for one's own feelings. These results are in accordance with the assumption suggesting more flexible and emotionally mature functioning in older adulthood due to the accumulation of experience with various emotions during the life course (Blanchard-Fields, 2007, 2009). Participants of older age are suggested to have previous rich experience with various emotional episodes that have occurred during their life courses, and this experience may lead to a tendency to perceive further emotional experiences as less unique, novel or uncommon. At the same time, the accumulation of experience may also cause a repeated experience of similar emotional events. This may be an explanation for the age-related decrease in thinking about one's emotional reactions and experiences and searching for the reasons for one's own feelings. Simply put, repeated experience of similar emotional events may lead to future utilization of patterns and scripts from previously experienced emotional 
episodes stored in memory. The decreased thinking about one's emotional reactions and emotional experiences may even be considered to be adaptive, because it can save cognitive resources in older adulthood.

Contrasting the results of the present study with the research of age-related differences in divergent thinking (Palmiero, 2015; Palmiero, Di Giacomo, \& Passafiume, 2014) provides further interesting insights into the age-related pattern of cognitive aging. Previous research revealed that verbal divergent thinking seems to be preserved after the age of 40 years without any further decline in older age (Palmiero, 2015). These results are interpreted by the assumption that verbal proficiencies (expressive word knowledge, concept formation, comprehension of text and verbal working memory) remain relatively intact across the lifespan. In contrast, the results of the present study indicated that EC decreases as age increases. We suggest that the decrease of EC in older age is rather unrelated to the quality of verbal proficiencies. Instead, the decreased levels of EC in terms of emotional preparedness are suggested to be closely connected with the decreased cognitive effort to invest attention, time and energy into thinking about past emotional reactions and emotional experiences. Merely the decreased effort to invest the energy into the processing of past emotional events is hypothesized as being responsible for a decline of emotional preparedness with age.

Interestingly, this interpretation is in accordance with previous research on self-perspective that showed an age-related decrease in memory specificity (Piolino et al., 2006). The nature of memories of older adults has been found to be more generic and less specific than the memories of younger adults. The agerelated decline in recalling sensory-perceptive, affective and spatiotemporal details may also be responsible for the age-related decrease in emotional preparedness found in the present study. Participants of older age may invest less attention, time and energy into thinking about past emotional reactions and emotional experiences, because their affective memories lack detail and specificity. Thus, the decreased memory specificity may be responsible for lower engagement in thinking about one's own emotional reactions and experiences in older adulthood.

The results of the present study indicate that one of the three components of EC, emotional effectiveness/authenticity, does not change significantly across adulthood (Figure 1). Emotional effectiveness/authenticity did not show any increase, decrease or curvilinear age pattern. This component includes effective responding in situations requiring new or unusual emotional responses and the tendency to believe that emotions may help a person achieve his or her life goals. Contrasting stable emotional effectiveness/authenticity across adulthood with the age-related decrease in EC, emotional novelty as well as the emotional preparedness found in the present study may be inspiring for the formulation of a hypothesis for future research. It seems that the tendency to think about one's emotions and to evaluate one's emotions as novel and unique decreases with age. However, the ability to respond effectively in situations requiring new or unusual emotional responses seems to remain relatively intact across adulthood.

\section{Limitations}

The present study was not designed as a longitudinal study. Despite the presented results, the present study cannot show how EC varies during the life of individuals. Future research utilizing a longitudinal design is needed in this field. The obtained results could also be affected by possible cohort effects. For example, it is not clear if older participants experienced different cultural conditions compared to younger participants. Furthermore, our findings are based on the utilization of a self-report questionnaire; thus, the data arises from the participants' own perceptions of their emotionally creative abilities. At present, the Emotional Creativity Inventory (Averill, 1999) is the only available method for measuring emotional creativity. The development of a new, objective measure of emotional creativity is a big chal- 
lenge for future methodological development in this field.

\section{Conclusion}

Previous research has shown that older adults have decreased cognitive creativity (Palmiero, Nori, \& Piccardi, 2017) as well as other decreased cognitive abilities, like working memory, processing speed, reasoning and higher-level executive functions (Salthouse et al., 2003; Salthouse, 2010). The present study contributes to this field and shows that age was negatively associated with the $\mathrm{ECl}$ total score and two components of the $\mathrm{ECl}$, emotional novelty and emotional preparedness. In contrast, age was not associated with the third component of EC, emotional effectiveness/ authenticity. Taken together, the results of the present study indicate that the tendency to think about one's emotions and to evaluate one's emotions as novel and unique decrease with age, whereas the ability to respond effectively in situations requiring new or unusual emotional responses does not change significantly across adulthood.

\section{Acknowledgement}

The collection, analysis, and interpretation of data as well as writing this manuscript were supported by the Czech Science Foundation (GA CR), project no. 18-26094S "Emotional creativity and cognitive decline in the elderly".

\section{References}

Averill, J. R. (1999). Individual differences in emotional creativity: Structure and correlates. Journal of Personality, 67(2), 331-371. https://doi.org/ 10.1111/1467-6494.00058

Banich, M. T., Mackiewicz, K. L., Depue, B. E., Whitmer, A. J., Miller, G. A., \& Heller, W. (2009). Cognitive control mechanisms, emotion and memory: A neural perspective with implications for psychopathology. Neuroscience \& Biobehavioral Reviews, 33(5), 613-630. https://doi.org/ 10.1016/j.neubiorev.2008.09.010

Blanchard-Fields, F. (2007). Everyday problem solving and emotion: An adult developmental perspec- tive. Current Directions in Psychological Science, 16(1), 26-31. https://doi.org/10.1111/j.14678721.2007.00469.x

Blanchard-Fields, F. (2009). Flexible and adaptive socio-emotional problem solving in adult development and aging. Restorative Neurology and Neuroscience, 27(5), 539-550. https://doi.org/ 10.3233/RNN-2009-0516

Blatný, M., Květon, P., Jelínek, M., Šolcová, I., Zábrodská, K., Mudrák, J., \& Machovcová, K. (2018). The influence of personality traits on life satisfaction through work engagement and job satisfaction among academic faculty members. Studia Psychologica, 60(4), 274-286. https:// doi.org/10.21909/sp.2018.04.767

Bloch, L., Haase, C. M., \& Levenson, R. W. (2014). Emotion regulation predicts marital satisfaction: More than a wives' tale. Emotion, 14(1), 130-144. https://doi.org/10.1037/a0034272

Brummer, L., Stopa, L., \& Bucks, R. (2014). The influence of age on emotion regulation strategies and psychological distress. Behavioural and Cognitive Psychotherapy, 42(6), 668-681. https://doi.org/ $10.1017 / S 1352465813000453$

Carstensen, L. L., Pasupathi, M., Mayr, U., \& Nesselroade, J. R. (2000). Emotional experience in everyday life across the adult life span. Journal of Personality and Social Psychology, 79, 644-655. https://doi.org/10.1037/0022-3514.79.4. 644

Charles, S. T. (2005). Viewing injustice: Greater emotion heterogeneity with age. Psychology and Aging, 20(1), 159-164. https://doi.org/10.1037/ 0882-7974.20.1.159

Eldesouky, L., \& English, T. (2018). Another year older, another year wiser? Emotion regulation strategy selection and flexibility across adulthood. Psychology and Aging, 33(4), 572-585. https://doi.org/ 10.1037/pag0000251

Finke, R. A., Ward, T. B., \& Smith, S. M. (1992). Creative cognition: Theory, research and application. Cambridge: MIT Press.

Foos, P. W., \& Boone, D. (2008). Adult age differences in divergent thinking: It's just a matter of time. Educational Gerontology, 34(7), 587-594. https://doi.org/10.1080/03601270801949393

Frolova, S. V., \& Novoselova, K. I. (2015). Emotional creativity as a factor of individual and family psychological wellbeing. International Annual Edition of Applied Psychology: Theory, Research, and Practice, 2, 30-43.

Grühn, D., Lumley, M. A., Diehl, M., \& Labouvie-Vief, G. (2013). Time-based indicators of emotional complexity: Interrelations and correlates. Emotion, 13(2), 226-237. https://doi.org/10.1037/a0030363 
Gutbezahl, J., \& Averill, J. R. (1996). Individual differences in emotional creativity as manifested in words and pictures. Creativity Research Journal, 9(4), 327-337. https://doi.org/10.1207/ s15326934crj0904 4

Guilford, J. P. (1967). Creativity: Yesterday, today and tomorrow. The Journal of Creative Behavior 1, 3-14. https://doi.org/10.1002/j.2162-6057. 1967.tb00002.x

Hay, E. L., \& Diehl, M. (2011). Emotion complexity and emotion regulation across adulthood. European Journal of Ageing, 8(3), 157-168. https://doi.org/ 10.1007/s10433-011-0191-7

Hopp, H., Troy, A. S., \& Mauss, I. B. (2011). The unconscious pursuit of emotion regulation: Implications for psychological health. Cognition and Emotion, 25(3), 532-545. https://doi.org/10.1080/ 02699931.2010 .532606

Humphreys, J., Jiao, N., \& Sadler, T. (2008). Emotional disposition and leadership preferences of American and Chinese MBA students. International Journal of Leadership Studies, 3(2), 162-180.

Ivcevic, Z., Brackett, M. A., \& Mayer, J. D. (2007). Emotional intelligence and emotional creativity. Journal of Personality, 75(2), 199-236. https:// doi.org/10.1111/j.1467-6494.2007.00437.x

John, O. P., \& Gross, J. J. (2004). Healthy and unhealthy emotion regulation: Personality processes, individual differences, and life span development. Journal of Personality, 72(6), 13011334. https://doi.org/10.1111/j.1467-6494.2004. 00298.x

Joormann, J., \& Quinn, M. E. (2014). Cognitive processes and emotion regulation in depression. Depression and Anxiety, 31(4), 308-315. https:// doi.org/10.1002/da.22264

Labouvie-Vief, G., DeVoe, M., \& Bulka, D. (1989). Speaking about feelings: Conceptions of emotion across the life span. Psychology and Aging, 4(4), 425-437. https://doi.org/10.1037/0882-7974.4. 4.425

Labouvie-Vief, G., Chiodo, L. M., Goguen, L. A., Diehl M., \& Orwoll, L. (1995). Representations of self across the life span. Psychology and Aging, 10(3), 404-415. https://doi.org/10.1037/0882-7974.10. 3.404

Labouvie-Vief, G., Diehl, M., Jain, E., \& Zhang, F. (2007). Six-year change in affect optimization and affect complexity across the adult life span: A further examination. Psychology and Aging, 22(4), 738-751. https://doi.org/10.1037/0882-7974.22. 4.738

Le Vigouroux, S., Pavani, J. B., Dauvier, B., Kop, J. L., \& Congard, A. (2017). Reactive or proactive? Age differences in the use of affective regulation strategies. Psychology and Aging, 32(7), 621-627. https://doi.org/10.1037/pag0000197

Limonero, J. T., Tomás Sábado, J., Fernández Castro, J., Gómez Romero, M. J., \& Ardilla Herrero, A. (2012). Resilient coping strategies and emotion regulation: Predictors of life satisfaction. Psicología Conductual, 20(1), 183-196.

Lindauer, M. (1998). Artists, art and arts activities: What do they tell us about aging? In C. E. AdamsPrice (Ed.), Creativity \& successful aging: Theoretical and empirical approaches (pp. 237-250). New York, NY: Springer.

Lohani, M., \& Isaacowitz, D. M. (2014). Age differences in managing response to sadness elicitors using attentional deployment, positive reappraisal and suppression. Cognition \& Emotion, 28(4), 678-697. https://doi.org/10.1080/02699931.2013. 853648

Martsksvishvili, K., Abuladze, N., Sordia, N., \& Neubauer, A. (2017). Emotional creativity inventory: Factor structure, reliability and validity in a Georgian-speaking population. Problems of Psychology in the 21st Century, 11(1), 31-41.

Masumoto, K., Taishi, N., \& Shiozaki, M. (2016). Age and gender differences in relationships among emotion regulation, mood, and mental health. Gerontology and Geriatric Medicine, 2, 1-8. https://doi.org/10.1177/2333721416637022

Morgan, E. S., \& Scheibe, S. (2014). Reconciling cognitive decline and increased well-being with age: The role of increased emotion regulation efficiency. In P. Verhaeghen \& C. Hertzog (Eds.), The Oxford handbook of emotion, social cognition, and everyday problem solving during adulthood (pp. 155171). New York, NY: Oxford University Press

Nolen-Hoeksema, S., \& Aldao, A. (2011). Gender and age differences in emotion regulation strategies and their relationship to depressive symptoms. Personality and Individual Differences, 51(6), 704-708. https://doi.org/10.1016/j.paid.2011.06. 012

Palmiero, M. (2015). The effects of age on divergent thinking and creative objects production: A crosssectional study. High Ability Studies, 26(1), 93104. https://doi.org/10.1080/13598139.2015. 1029117

Palmiero, M., Di Giacomo, D., \& Passafiume, D. (2014). Divergent thinking and age-related changes. Creativity Research Journal, 26(4), 456-460. https://doi.org/10.1080/10400419.2014. 961786

Palmiero, M., Nori, R., \& Piccardi, L. (2017). Verbal and visual divergent thinking in aging. Experimental Brain Research, 235(4), 1021-1029. https:// doi.org/10.1007/s00221-016-4857-4 
Phillips, L. H., Henry, J. D., Hosie, J. A., \& Milne, A. B. (2008). Effective regulation of the experience and expression of negative affect in old age. The Journals of Gerontology Series B: Psychological Sciences and Social Sciences, 63(3), 138-145. https://doi.org/10.1093/geronb/63.3.P138

Piolino, P., Desgranges, B., Clarys, D., Guillery-Girard, B., Taconnat, L., Isingrini, M., \& Eustache, F. (2006). Autobiographical memory, autonoetic consciousness, and self-perspective in aging. Psychology and Aging, 21(3), 510-525. https://doi.org/ 10.1037/0882-7974.21.3.510

Ram, N., Gerstorf, D., Lindenberger, U., \& Smith, J. (2011). Developmental change and intraindividual variability: Relating cognitive aging to cognitive plasticity, cardiovascular lability, and emotional diversity. Psychology and Aging, 26(2), 363-371. https://doi.org/10.1037/a0021500

Reese, H. W., Lee, L. J., Cohen, S. H., \& Puckett, J. M. (2001). Effects of intellectual variables, age, and gender on divergent thinking in adulthood. International Journal of Behavioral Development, 25(6), 491-500. https://doi.org/10.1080/ 01650250042000483

Roskos-Ewoldsen, B., Black, S. R., \& McCown, S. M. (2008). Age-related changes in creative thinking. The Journal of Creative Behavior, 42, 33-59. https://doi.org/10.1002/j.2162-6057.2008. tb01079.x

Runco, M. A., \& Jaeger, G. J. (2012). The standard definition of creativity. Creativity Research Journal, 24(1), 92-96. https://doi.org/10.1080/ 10400419.2012.650092

Salthouse, T. A., Atkinson, T. M., \& Berish, D. E. (2003). Executive functioning as a potential mediator of age-related cognitive decline in normal adults. Journal of Experimental Psychology: General, 132(4), 566-594. https://doi.org/10.1037/ 0096-3445.132.4.566

Salthouse, T. (2010). Major issues in cognitive aging (Vol. 49). Oxford: Oxford University Press. https://doi.org/10.1093/acprof:oso/ 9780195372151.001. 0001
Shiota, M. N., \& Levenson, R. W. (2009). Effects of aging on experimentally instructed detached reappraisal, positive reappraisal, and emotional behavior suppression. Psychology and Aging, 24(4), 890-900. https://doi.org/10.1037/a0017896

Scheibe, S., \& Blanchard-Fields, F. (2009). Effects of regulating emotions on cognitive performance: What is costly for young adults is not so costly for older adults. Psychology and Aging, 24(1), 217223. https://doi.org/10.1037/a0013807

Schutte, N. S., Manes, R. R., \& Malouff, J. M. (2009). Antecedent-focused emotion regulation, response modulation and well-being. Current Psychology, 28(1), 21-31. https://doi.org/10.1007/s12144009-9044-3

Szczesniak, M., \& Timoszyk-Tomczak, C. (2018). A time for being thankful: Balanced time perspective and gratitude. Studia Psychologica, 60(3), 150-166. https://doi.org/10.21909/sp.2018.03. 759

Trnka, R., Zahradnik, M., \& Kuška, M. (2016). Emotional creativity and real-life involvement in different types of creative leisure activities. Creativity Research Journal, 28(3), 348-356. https://doi.org/ 10.1080/10400419.2016.1195653

Trnka, R., Cabelkova, I., Kuška, M., \& Nikolai, T. (2019). Cognitive decline influences emotional creativity in the elderly. Creativity Research Journal, 31(1), 93-101. https://doi.org/10.1080/10400419.2019. 1577205

Vater, A., \& Schröder-Abé, M. (2015). Explaining the link between personality and relationship satisfaction: Emotion regulation and interpersonal behaviour in conflict discussions. European Journal of Personality, 29(2), 201-215. https://doi.org/ 10.1002/per. 1993

Zenasni, F., \& Lubart, T. I. (2008). Emotion-related traits moderate the impact of emotional state on creative performances. Journal of Individual Differences, 29(3), 157-167. https://doi.org/10.1027/ 1614-0001.29.3.157 